\title{
Immunogenicity and safety of intradermal influenza vaccine in immunocompromized patients: a meta-analysis of randomized controlled trials
}

Claudia Pileggi, Francesca Lotito, Aida Bianco, Carmelo G. A. Nobile and Maria Pavia*

\begin{abstract}
Background: The primary influenza prevention strategy is focused on annual vaccination according to the categories identified in the various countries as being at greatest risk of complications. Many studies were conducted in order to demonstrate that intradermal (ID) vaccine formulation represents a promising alternative to conventional intramuscular (IM) formulation, especially in subjects with an impaired immune system. However, there is no consensus whether the efficacy and safety of ID is equivalent to IM in these subjects. Therefore, we performed a meta-analysis of Randomized Controlled Trials (RCT) to compare the immunogenicity and safety of ID and IM influenza vaccines in subjects with a depleted immune system.

Methods: We conducted a search strategy of medical literature published until November 2014 in order to identify RCTs that evaluated the immunogenicity and safety of ID compared with IM influenza vaccines in immunocompromized patients.

Results: We identified a total of 269 citations through research in electronic databases and scanning reference lists. Of these, 6 articles were included in the meta-analysis, for a total of 673 subjects. The seroprotection rate induced by the ID vaccine is comparable to that elicited by the IM vaccine. The overall RR was 1.00 ( $95 \% \mathrm{Cl}=0.91-1.10$ ) for A/ $\mathrm{H} 1 \mathrm{~N} 1$ strain, $1.00(95 \% \mathrm{Cl}=0.90-1.12)$ for $\mathrm{A} / \mathrm{H} 3 \mathrm{~N} 2$ and $0.99(95 \% \mathrm{Cl}=0.84-1.16)$ for $\mathrm{B}$ strain. No significant differences in the occurrence of systemic reactions were detected (17.7\% in the ID group vs $18.2 \%$ in the IM group) with a pooled $\mathrm{RR}=1.00(95 \% \mathrm{Cl}=0.67-1.51)$, whereas ID administration caused significantly more injection site reactions with a mean frequency of $46 \%$ in the ID group compared to $22 \%$ in the IM group, with a pooled RR $=1.89$ (95\% $\mathrm{Cl}=1.40-2.57)$.
\end{abstract}

Conclusions: The ID influenza vaccine has shown a similar immunogenicity and safety to the IM influenza vaccine in immunocompromized patients, and it may be a valid option to increase compliance to influenza vaccination in these populations.

Keywords: Influenza vaccine, Intradermal, Intramuscular, Immunocompromized patients

\footnotetext{
*Correspondence: pavia@unicz.it

Department of Health Sciences, University of Catanzaro "Magna Græcia", Via

Tommaso Campanella, 88100 Catanzaro, Italy
}

(c) 2015 Pileggi et al. Open Access This article is distributed under the terms of the Creative Commons Attribution 4.0 International License (http://creativecommons.org/licenses/by/4.0/), which permits unrestricted use, distribution, and reproduction in any medium, provided you give appropriate credit to the original author(s) and the source, provide a link to the Creative Commons license, and indicate if changes were made. The Creative Commons Public Domain Dedication waiver (http://creativecommons.org/publicdomain/zero/1.0/) applies to the data made available in this article, unless otherwise stated. 


\section{Background}

The primary influenza prevention strategy is focused on annual vaccination according to the categories identified as being at greatest risk of complications. Recently, in the United States, the recommendations for influenza vaccination has been extended to a larger population by the Advisory Committee on Immunization Practices (ACIP) $[1,2]$, and all subjects aged $\geq 6$ months were included.

The common route of influenza vaccine administration is intramuscular (IM) but, more recently, an intradermal (ID) vaccine formulation, licensed in the European Union in February 2009 and by the Food and Drug Administration (FDA) in May 2011, has become available.

Among the several strategies investigated to increase the immunogenicity of influenza vaccine, researchers have focused attention on ID formulation that appears a valid alternative to IM route because this mode of delivery may be advantageous in terms of immunogenicity, dose sparing, greater acceptability among the patients and lower risk of accidental puncture for healthcare workers, because needle-free injection devices can evoke less pain and stress in patients and avoid unsafe injection practices, in line with the World Health Organization (WHO) objectives [3, 4].

Many studies have been conducted in order to demonstrate that the ID influenza vaccine represents a promising alternative to the IM formulation, especially in subjects with a limited vaccination response caused by an impairment of the immune defenses as a result of many different mechanisms, such as treatment with immunosuppressive drugs or HIV infection [5-7]. However, there is no consensus whether the immunogenicity and safety of the ID vaccine is equivalent to the IM formulation in these subjects. Therefore, we performed a meta-analysis of Randomized Controlled Trials (RCT) to compare the immunogenicity and safety of ID and IM influenza vaccine in immunocompromized subjects.

\section{Methods}

\section{Search strategy for identification of studies}

We conducted a search strategy of medical literature published until November 2014 in order to identify RCTs that evaluated the immunogenicity and safety of ID influenza vaccines compared with IM influenza vaccines in immunocompromized patients. The U.S. National Library of Medicine (MEDLINE), Embase, Cochrane Central Register of Controlled Trials, Scopus and Monthly Influenza Bibliography of the National Institute for Medical Research electronic database were searched. Also, we reviewed the reference lists from all retrieved publications and the most recent review articles, in order to identify additional undetected published studies.
The following Medical Subject Heading (MeSH) terms were used individually and in combination in the search: "autoimmune disease", "cancer", "comparison", "HIV infection", "immunodeficiency disorder", "immunosuppressive therapy", "influenza vaccine", "intradermal administration", "meta-analysis", "randomized controlled trials", "transplant recipients".

\section{Inclusion criteria}

Articles that met the following criteria were included: (a) RCTs; (b) primary studies; (c) enrollment of all kinds of immunocompromized patients; (d) comparing the immunogenicity and/or safety of the ID vaccine with the standard IM vaccine measuring one or more of the following outcomes: seroprotection and/or seroconversion rate to assess immunogenicity, local reactions and/or general symptoms as safety indicators, according to European Medicines Agency (EMA) criteria; (e) published through November 2014. Trials that compared ID influenza vaccine with IM administration in healthy population, studies that used pandemic vaccine, re-analyses, reviews, letters and abstracts were excluded.

\section{Assessment of study quality}

Two of the authors independently reviewed the studies included in the meta-analysis to appraise the quality of the individual trials using criteria developed by Chalmers et al. [8] and the method of Jadad et al. [9]. Studies were classified as high quality if their score was higher than the median calculated for each quality scale.

\section{Data extraction}

The following data were collected from each study: (a) name of first author, year of publication, and geographic setting; (b) study design; (c) description of intervention in the ID and IM group; (e) number of subjects in each group; f) patient characteristics (age, gender and cause of impairment of the immune system); g) outcome data: 1) percentage of subjects with a post-vaccination titer $\geq 40$ for each strain, referred as the seroprotection rate; 2) percentage of subjects with either a pre-vaccination titer $<10$ and a postvaccination titer $\geq 40$, or a fourfold rise in titer from a pre-vaccination titer $\geq 10$, defined as the seroconversion rate; 3) percentage of subjects with at least one injection site reaction (pain, erythema, swelling, pruritus, induration and ecchymosis); 4) percentage of subjects with at least one systemic sign or symptom (fever, myalgia, headache, malaise and shivering).

\section{Statistical analysis}

Risk Ratio (RR) of seroprotection was calculated as the ratio of the percentage of subjects in which seroprotection occurred in those who received ID formulation 
compared with those who received traditional IM formulation. Similarly, the RR of seroconversion was calculated as the ratio of the percentage of subjects in which seroconversion occurred in ID and IM group. Safety was assessed as the ratio of the percentage of participants that had at least one local and/or general adverse event associated with the ID vaccine compared with those who received the IM vaccine. All meta-analyses were carried out using the DerSimonian and Laird random-effect model [10]. The Mantel-Haenszel method (fixed effects model) [11] was also used. Statistical heterogeneity was assessed using Cochran $\mathrm{Q}$ and $\mathrm{I}^{2}$ measure; an $\mathrm{I}^{2}$ value above $25 \%$ may be considered low heterogeneity, a value above $50 \%$ and $75 \%$ were predefined as moderate and high heterogeneity [12].

\section{Sensitivity analyses}

To explore the reasons for heterogeneity, we performed separate sensitivity analyses by pooling studies that involved subjects with similar characteristics (i.e. having a similar disease that causes immunodeficiency), details of intervention as antigen content, type of ID devices used, and number of injection sites. Also, we performed a metaanalysis to assess the potential effect of the studies' quality on the results, by combining only studies with Jadad scores greater than or equal to the median (high quality).

Finally, publication bias was explored by searching eventual unpublished RCTs in two clinical trial registries: ClinicalTrials.gov and EudraCT.

All statistical analyses were performed using Stata software program, version 11 (Stata Corporation. College Station, TX).

The reporting of study's findings was in accordance with the PRISMA statement [13]. PRISMA checklist was used to ensure inclusion of relevant information (See Additional file 1).

\section{Results}

\section{Study characteristics}

We identified a total of 269 citations through research in electronic database and scanning references lists. Of these, 6 articles [14-19] met all inclusion criteria and were available for the meta-analysis. A flow diagram describes the reasons for excluding the studies from the meta-analysis (Fig. 1). In particular, only two studies performed in immunocompromized patients were excluded: the first because it was a letter [20] and the second because it verified the role of a booster dose of ID injection in patients vaccinated with a standard dose of IM injection [21].

The main characteristics and extracted data of the included RCTs are summarized in Table 1. The studies were carried out from 2009 until 2013. Patients were 1877 years old, with a mean age of 48 to 54 in the ID group and 48 to 55 years in the IM group. Males accounted for $50 \%$ to $73 \%$ of participants in the ID group and $47 \%$ to $68 \%$ in the IM group. In 3 studies participants were transplant recipients [16, 17, 19], whilst one other involved patients with solid tumors [15], and another comprised of HIV-infected patients [18] and the remaining study was conducted in patients with different diseases causing immunosuppression [14]. ID trivalent inactivated split-virion vaccine was used in 5 studies [15-19] and in the remaining one a subunit vaccine was used [14]; the antigen content ranged from 3 to $15 \mu \mathrm{g}$ hemagglutinin (HA)/strain. In the IM group, the traditional vaccination with the same amount of antigen (15 $\mu \mathrm{g} \mathrm{HA})$ of the trivalent inactivated split-virion vaccine was used in all trials. In 2 studies, ID vaccine was administered at two separate injection sites [17, 19]. Two studies used Mantoux technique [14, 15], while in the others the devices employed were microneedles [18] and microinjection systems $[16,17,19]$.

Only one trial did not report local and systemic reactions [19], in one study they were pooled [14], in the remaining studies each local and systemic adverse reaction was reported for IM and ID group [15-18]. In 3 studies also subjects with at least one local [16-18] or systemic [15-17] reaction were reported and these values were extracted for the meta-analysis, in others the most frequent local [15] or systemic [18] reaction was extracted. Local reactions ranged from $19 \%$ to $80.6 \%$ in the ID group and from $5.5 \%$ to $48.4 \%$ in the IM group, with an overall frequency of $46 \%$ in the ID group and of $22 \%$ in the IM group. In the ID group the most frequent local reactions were erythema and swelling followed by pruritus, whereas pain was reported only in two studies $[15,16]$ and the frequency was similar in the ID and IM group. Systemic adverse events ranged from $1.9 \%$ to $54.8 \%$ in the ID group and from $3.6 \%$ to $51.6 \%$ in the IM group (overall frequency $17.7 \%$ ID group vs $18.2 \%$ IM group). The most frequent systemic reported symptoms were shivering and headache.

\section{Data quality}

The mean quality scores of the individual studies using the Chalmers et al. [8] scale ranged from 0.32 to 0.75 (mean $=0.57$; median $=0.61)$. With regard to the Jadad et al. [9] criteria, the mean score was 2.8 (median 3), all trials were classified as open-label and reported a description of withdrawals or dropouts after randomization. According to the Jadad score only one study [15] was below the median, whereas according to the Chalmers score three studies were below the median [14-16]. Scores of individual studies are reported in Table 1. 


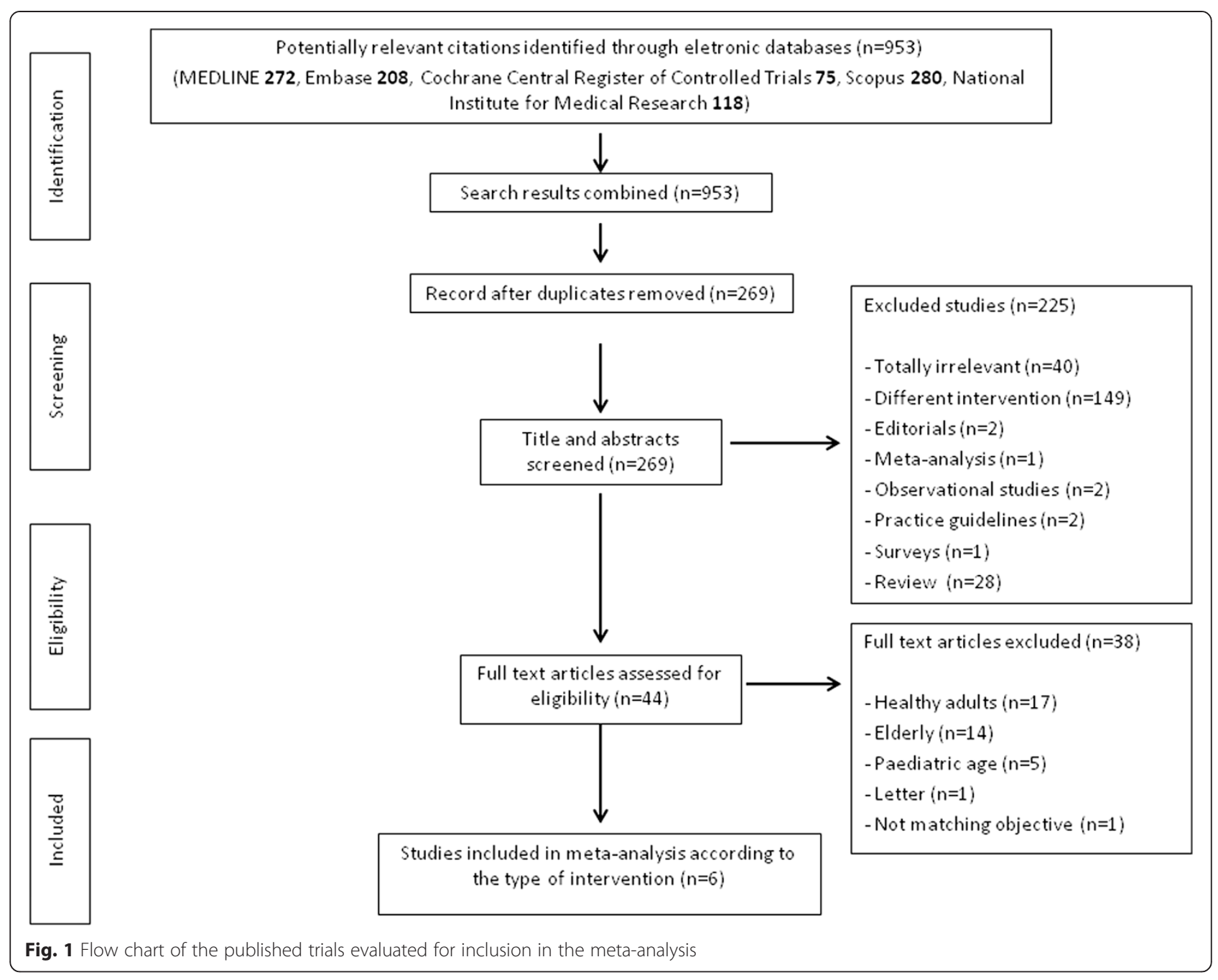

\section{Meta-analysis}

The results of the meta-analyses that compared the immunogenicity of the ID influenza vaccine with the IM vaccine involving 673 patients for the meta-analysis on seroprotection and 517 patients for that on seroconversion are shown in Table 2.

The seroprotection rate induced by the ID vaccine was comparable to that elicited by the IM vaccine. The overall RR was 1.00 (95\% CI = 0.91-1.10) for A/H1N1 strain, 1.00 (95\% CI $=0.90-1.12)$ for $\mathrm{A} / \mathrm{H} 3 \mathrm{~N} 2$ and 0.99 (95 \% $\mathrm{CI}=$ 0.84-1.16) for B strain. The $\mathrm{I}^{2}$ statistic test showed a lowmoderate heterogeneity (Fig. 2). Similarly, the seroconversion rate achieved with the ID vaccine was found to be equivalent to that of the IM vaccine for each strain (A/ H1N1: RR = 1.00, $95 \% \mathrm{CI}=0.84-1.19 ; \mathrm{A} / \mathrm{H} 3 \mathrm{~N} 2: \mathrm{RR}=1.08$, $95 \% \mathrm{CI}=0.86-1.36$; $\mathrm{B}: \mathrm{RR}=0.92,95 \% \mathrm{CI}=0.72-1.17)$ and no heterogeneity was found.

The meta-analyses on vaccine safety (Fig. 3), conducted on 4 trials to estimate injection site and systemic reactions, showed no significant differences in the occurrence of systemic side effects, with a pooled $\mathrm{RR}=1.00 \quad(95 \% \mathrm{CI}=0.67-1.51)$. ID administration caused significantly more injection site reactions $(\mathrm{RR}=$ $1.89,95 \% \mathrm{CI}=1.40-2.57)$. The $\mathrm{I}^{2}$ statistic test showed no heterogeneity across the trials both for systemic and for local side effects.

\section{Sensitivity analysis}

Pooled analyses after restriction to quality of the studies (high quality, low quality), to antigen content $(\leq 9 \mu \mathrm{g}, \geq 12 \mu \mathrm{g})$, to type of ID devices used (Mantoux technique, micro injection system), to number of injection sites (one injection, two injections) and to the cause of immunosuppression (transplantation, other diseases) showed that the investigated factors did not substantially influence the findings for all strains (Table 2).

In the sensitivity analyses on seroprotection, heterogeneity disappeared when analyses were stratified by antigen content $(\leq 9 \mu \mathrm{g})$ for the $\mathrm{A} / \mathrm{H} 3 \mathrm{~N} 2$ and $\mathrm{B}$ strains, by other causes of immunosuppression excluding 
Table 1 Characteristics of included RCTs on intradermal versus intramuscular administration of influenza vaccine

\begin{tabular}{|c|c|c|c|c|c|c|c|c|c|c|c|c|c|c|c|}
\hline \multirow[t]{5}{*}{ Authors } & \multirow[t]{5}{*}{ Country } & \multirow{3}{*}{\multicolumn{2}{|c|}{ Interventions }} & \multirow{5}{*}{$\begin{array}{l}\text { Units of } \\
\text { treatment } \\
\text { ID/IM }\end{array}$} & \multicolumn{6}{|c|}{ Immunogenicity } & \multicolumn{2}{|c|}{ Reported reactions } & \multirow[t]{5}{*}{ Population } & \multicolumn{2}{|c|}{ Quality score } \\
\hline & & & & & \multicolumn{3}{|c|}{ Seroprotection } & \multicolumn{3}{|c|}{ Seroconversion } & \multirow{2}{*}{$\begin{array}{l}\text { Injection } \\
\text { site }^{\mathrm{a}}\end{array}$} & \multirow[t]{2}{*}{ Systemic $^{b}$} & & \multirow{4}{*}{$\begin{array}{l}\text { Jadad } \\
\text { scale }\end{array}$} & \multirow{4}{*}{$\begin{array}{l}\text { Chalmers } \\
\text { scale }\end{array}$} \\
\hline & & & & & $\mathrm{A} / \mathrm{H} 1 \mathrm{~N} 1$ & $\mathrm{~A} / \mathrm{H} 3 \mathrm{~N} 2$ & B & $\mathrm{A} / \mathrm{H} 1 \mathrm{~N} 1$ & $\mathrm{~A} / \mathrm{H} 3 \mathrm{~N} 2$ & B & & & & & \\
\hline & & \multirow[t]{2}{*}{$\mathrm{ID}$} & \multirow[t]{2}{*}{ IM } & & N (\%) & $N(\%)$ & N (\%) & N (\%) & N (\%) & N (\%) & N (\%) & N (\%) & & & \\
\hline & & & & & $\mathrm{ID} / \mathrm{IM}$ & $\mathrm{ID} / \mathrm{IM}$ & $\mathrm{ID} / \mathrm{IM}$ & $\mathrm{ID} / \mathrm{IM}$ & $\mathrm{ID} / \mathrm{IM}$ & $\mathrm{ID} / \mathrm{IM}$ & $\mathrm{ID} / \mathrm{IM}$ & $\mathrm{ID} / \mathrm{IM}$ & & & \\
\hline \multirow{2}{*}{$\begin{array}{l}\text { L Gelinck et al. } \\
2009 \text { [14] }\end{array}$} & \multirow[t]{2}{*}{ Netherlands } & TIV SU & TIV SU & \multirow[t]{2}{*}{$77 / 79$} & \multirow{2}{*}{$\begin{array}{l}49(63.6) / \\
60(75.9)\end{array}$} & \multirow{2}{*}{$\begin{array}{l}60(77.9) / \\
58(73.4)\end{array}$} & \multirow{2}{*}{$\begin{array}{l}50(64.9) / \\
55(69.6)\end{array}$} & \multirow[t]{2}{*}{ NA } & \multirow[t]{2}{*}{ NA } & \multirow[t]{2}{*}{ NA } & \multicolumn{2}{|c|}{ Total reactions ${ }^{c}$} & \multirow{2}{*}{$\begin{array}{l}\text { Immuno- } \\
\text { compromized } \\
\text { patients }\end{array}$} & \multirow[t]{2}{*}{$3 / 5$} & \multirow[t]{2}{*}{0.54} \\
\hline & & $\begin{array}{l}3 \mu \mathrm{g} \mathrm{HA} / \\
\text { strain }\end{array}$ & $\begin{array}{l}15 \mu \mathrm{g} \\
\mathrm{HA} / \mathrm{strain}\end{array}$ & & & & & & & & \multicolumn{2}{|c|}{$\begin{array}{c}52 \% \text { ID group } / 30 \% \text { IM } \\
\text { group }\end{array}$} & & & \\
\hline \multirow{2}{*}{$\begin{array}{l}\text { Y Jo et al. } 2009 \\
\text { [15] }\end{array}$} & \multirow[t]{2}{*}{ Korea } & TIV SPL & TIV SPL & \multirow[t]{2}{*}{$52 / 55$} & $50(96.1) /$ & $50(90.1) /$ & $41(78.8) /$ & 38(73)/ & $28(53.8) /$ & $28(53.8) /$ & $10(19) /$ & $1(1.9) /$ & Patients with & $2 / 5$ & 0.32 \\
\hline & & $\begin{array}{l}7.5 \mu \mathrm{g} \\
\mathrm{HA} / \mathrm{strain}\end{array}$ & $\begin{array}{l}15 \mu g \\
H A / s t r a i n\end{array}$ & & & & & & & & & & & & \\
\hline E Morelon & France & TIV SPL & TIV SPL & $31 / 31$ & $22(71) /$ & $16(52) /$ & $22(71) /$ & $11(35) /$ & $11(35) /$ & $6(19) / 6(19)$ & $25(80.6) /$ & $17(54.8) /$ & Renal transplant & $3 / 5$ & 0.45 \\
\hline & & $\begin{array}{l}15 \mu g \\
H A / s t r a i n\end{array}$ & $\begin{array}{l}15 \mu g \\
H A / s t r a i n\end{array}$ & & & & & & & & & & & & \\
\hline O Manuel et al. & Multicentric $^{f}$ & TIV SPL & TIV SPL & $41 / 43$ & $16(39) /$ & $34(83) /$ & $12(29) /$ & $3(7.3) /$ & $2(4.9) / 3(7)$ & $3(7.3) /$ & $17(41.5) /$ & $3(7.3) / 7$ & Lung transplant & $3 / 5$ & 0.67 \\
\hline $2011[1 /]$ & & $\begin{array}{l}6^{h} \mu g \\
H A / s t r a i n\end{array}$ & $\begin{array}{l}15 \mu \mathrm{g} \\
\mathrm{HA} / \mathrm{strain}\end{array}$ & & & & & & & & $11(2 J)$ & & & & \\
\hline F Ansaldi et al. & Italy & TIV SPL & TIV SPL & $28 / 24$ & $22(79) /$ & $23(82) /$ & $21(75) /$ & $14(50) /$ & $15(54) /$ & $11(36) /$ & $18(64.3) /$ & $6(21.4) /$ & HIV-infected & $3 / 5$ & 0.71 \\
\hline & & $\begin{array}{l}9 \mu \mathrm{g} \mathrm{HA} / \\
\text { strain }\end{array}$ & $\begin{array}{l}15 \mu g \\
H A / s t r a i n\end{array}$ & & & & & & & & & & & & \\
\hline A Baluch et al. & Canada & TIV SPL & TIV SPL & 107/105 & $76(71) /$ & $\begin{array}{l}75(70.1) / \\
67(630)\end{array}$ & 68(63.6)/ & 40(37.4)/ & $31(29) /$ & $23(21.5) /$ & & & Transplant & $3 / 5$ & 0.75 \\
\hline & & $\begin{array}{l}9^{i} \mu g \\
H A / s t r a i n\end{array}$ & $\begin{array}{l}15 \mu g \\
\mathrm{HA} / \text { strain }\end{array}$ & & & & & & & & & & & & \\
\hline
\end{tabular}

ID: Intradermal; IM: Intramuscular; TIV: trivalent inactivated vaccine; HA: hemagglutinin; SPL: split vaccine; SU: subunit vaccine

apain at injection site, erythema, swelling, pruritus, induration and ecchymosis

${ }^{\mathrm{b}} \mathrm{Fever}$, myalgia, headache, malaise and shivering

${ }^{C}$ Frequency of local and systemic adverse reactions calculated on 125 participants that recorded whether or not they had suffered adverse reactions

${ }^{d}$ Referred to swelling that was the most frequent symptom suffered both in ID and IM groups

${ }^{\mathrm{e}}$ Referred to fever or myalgia

${ }^{f}$ Canada and Switzerland
${ }^{9}$ Referred to shivering that was the most frequent symptom suffered both in ID and IM groups

hTwo doses of ID vaccine was teliver for a cumulative sufe $12 \mu g$ antigen per stroup 
Table 2 Overall and sensitivity analysis results of immunogenicity of intradermal versus intramuscular administration of influenza vaccine

\begin{tabular}{|c|c|c|c|c|c|c|c|c|c|c|c|c|}
\hline \multirow[b]{2}{*}{ SEROPROTECTION } & \multicolumn{4}{|l|}{$\mathrm{H} 1 \mathrm{~N} 1$} & \multicolumn{4}{|l|}{$\mathrm{H} 3 \mathrm{~N} 2$} & \multicolumn{4}{|l|}{$B$} \\
\hline & $\begin{array}{l}\text { No. } \\
\text { studies }\end{array}$ & $\begin{array}{l}\text { No. } \\
\text { patients }\end{array}$ & $\begin{array}{l}\text { Overall RR (95 \% } \\
(\mathrm{Cl})^{\mathrm{a}}\end{array}$ & $\begin{array}{l}\text { Heterogeneity } \\
\text { test }\left(p ;\left.\right|^{2} \%\right)\end{array}$ & No. studies & No. patients & $\begin{array}{l}\text { Overall RR (95 \% } \\
(\mathrm{Cl})^{\mathrm{a}}\end{array}$ & $\begin{array}{l}\text { Heterogeneity } \\
\text { test }\left(p ; 1^{2} \%\right)\end{array}$ & $\begin{array}{l}\text { No. } \\
\text { studies }\end{array}$ & $\begin{array}{l}\text { No. } \\
\text { patients }\end{array}$ & $\begin{array}{l}\text { Overall RR (95 \% } \\
(\mathrm{CI})^{\mathrm{a}}\end{array}$ & $\begin{array}{l}\text { Heterogeneity } \\
\text { test }\left(p ; 1^{2} \%\right)\end{array}$ \\
\hline All studies & 6 & 673 & $1.00(0.91-1.1)$ & $0.272 ; 21.5$ & 6 & 673 & $1.00(0.9-1.12)$ & $0.042 ; 56.6$ & 6 & 673 & $0.99(0.84-1.16)$ & $0.072 ; 50.5$ \\
\hline High quality ${ }^{b}$ & 5 & 566 & $1.01(0.86-1.18)$ & $0.177 ; 36.7$ & 5 & 566 & $1.02(0.88-1.19)$ & $0.05 ; 57.9$ & 5 & 566 & $0.98(0.79-1.22)$ & $0.041 ; 59.8$ \\
\hline Low quality ${ }^{b}$ & 1 & 107 & $1.02(0.94-1.11)$ & - & 1 & 107 & $0.98(0.92-1.05)$ & - & 1 & 107 & $0.94(0.79-1.16)$ & - \\
\hline Antigen content $\geq 12 \mu \mathrm{g}$ & 3 & 358 & $1.13(0.9-1.43)$ & $0.248 ; 28.4$ & 3 & 358 & $1.03(0.77-1.39)$ & $0.01 ; 78.4$ & 3 & 358 & $0.94(0.61-1.47)$ & $0.01 ; 78.1$ \\
\hline Antigen content $\leq 9 \mu \mathrm{g}$ & 3 & 315 & $0.95(0.8-1.14)$ & $0.067 ; 63$ & 3 & 315 & $0.99(0.93-1.05)$ & $0.368 ; 0.1$ & 3 & 315 & $0.96(0.84-1.09)$ & $0.935 ; 0$ \\
\hline One injection & 4 & 377 & $0.99(0.86-1.15)$ & $0.136 ; 45.9$ & 4 & 377 & $1.04(0.9-1.2)$ & $0.087 ; 54.3$ & 4 & 377 & $0.98(0.87-1.11)$ & $0.783 ; 0$ \\
\hline Two injections & 2 & 296 & $1.05(0.84-1.3)$ & $0.291 ; 10.2$ & 2 & 296 & $0.96(0.72-1.29)$ & $0.015 ; 83.1$ & 2 & 296 & $0.8(0.34-1.99)$ & $0.003 ; 88.8$ \\
\hline Mantoux technique & 2 & 263 & $0.93(0.71-1.24)$ & $0.012 ; 84$ & 2 & 263 & $1.00(0.89-1.13)$ & $0.177 ; 45.2$ & 2 & 263 & $0.95(0.82-1.1)$ & $0.819 ; 0$ \\
\hline Micro injection system & 4 & 410 & $1.06(0.92-1.22)$ & $0.378 ; 2.9$ & 4 & 410 & $1.02(0.83-1.26)$ & $0.027 ; 67.4$ & 4 & 410 & $0.98(0.73-1.32)$ & $0.027 ; 67.4$ \\
\hline \multicolumn{13}{|c|}{ Cause of immunosuppression: } \\
\hline Transplantation & 4 & 344 & $1.11(0.86-1.43)$ & $0.228 ; 30.7$ & 4 & 344 & $1.04(0.8-1.35)$ & $0.22 ; 68.9$ & 4 & 344 & $0.91(0.61-1.36)$ & $0.018 ; 70.2$ \\
\hline Other diseases $^{b}$ & 3 & 488 & $0.98(0.87-1.1)$ & $0.216 ; 34.7$ & 3 & 488 & $0.99(0.93-1.05)$ & $0.465 ; 0$ & 4 & 488 & $0.97(0.86-1.1)$ & $0.98 ; 0$ \\
\hline \multicolumn{13}{|l|}{ SEROCONVERSION } \\
\hline All studies & 5 & 517 & $1.00(0.84-1.19)$ & $0.532 ; 0$ & 5 & 517 & $1.08(0.86-1.36)$ & $0.569 ; 0$ & 5 & 517 & $0.92(0.72-1.17)$ & $0.578 ; 0$ \\
\hline High quality ${ }^{b}$ & 4 & 410 & $1.04(0.79-1.36)$ & $0.399 ; 0$ & 4 & 410 & $1.00(0.75-1.34)$ & $0.52 ; 0$ & 4 & 410 & $1.13(0.77-1.66)$ & $0.823 ; 0$ \\
\hline Low quality ${ }^{b}$ & 1 & 107 & $0.98(0.78-1.23)$ & - & 1 & 107 & $1.23(0.83-1.83)$ & - & 1 & 107 & $0.80(0.59-1.09)$ & - \\
\hline Antigen content $\geq 12 \mu \mathrm{g}$ & 3 & 358 & $1.17(0.85-1.62)$ & $0.545 ; 0$ & 3 & 358 & $1.06(0.73-1.55)$ & $0.36 ; 2$ & 3 & 358 & $1.11(0.7-1.75)$ & $0.641 ; 0$ \\
\hline Antigen content $\leq 9 \mu \mathrm{g}$ & 2 & 159 & $0.95(0.77-1.16)$ & $0.443 ; 0$ & 2 & 159 & $1.1(0.81-1.45)$ & $0.35 ; 0$ & 2 & 159 & $0.85(0.64-1.13)$ & $0.33 ; 0$ \\
\hline One injection & 3 & 221 & $0.99(0.74-1.34)$ & $0.242 ; 29.6$ & 3 & 221 & $1.16(0.86-1.57)$ & $0.341 ; 7$ & 3 & 221 & $0.86(0.65-1.13)$ & $0.589 ; 0$ \\
\hline Two injections & 2 & 296 & $1.09(0.77-1.55)$ & $0.961 ; 0$ & 2 & 296 & $0.94(0.63-1.4)$ & $0.735 ; 0$ & 2 & 296 & $1.14(0.68-1.9)$ & $0.359 ; 0$ \\
\hline Mantoux technique & 1 & 107 & $0.98(0.78-1.23)$ & - & 1 & 107 & $1.23(0.83-1.83)$ & - & 1 & 107 & $0.80(0.59-1.09)$ & - \\
\hline Micro injection system & 4 & 410 & $1.04(0.79-1.36)$ & $0.399 ; 0$ & 4 & 410 & $1.00(0.75-1.34)$ & $0.52 ; 0$ & 4 & 410 & $1.13(0.77-1.66)$ & $0.823 ; 0$ \\
\hline \multicolumn{13}{|c|}{ Cause of immunosuppression: } \\
\hline Transplantation & 3 & 358 & $1.17(0.85-1.62)$ & $0.545 ; 0$ & 3 & 358 & $1.06(0.73-1.55)$ & $0.36 ; 2$ & 3 & 358 & $1.11(0.7-1.75)$ & $0.641 ; 0$ \\
\hline Other diseases ${ }^{c}$ & 2 & 159 & $0.95(0.77-1.16)$ & $0.443 ; 0$ & 2 & 159 & $1.1(0.81-1.45)$ & $0.35 ; 0$ & 2 & 159 & $0.85(0.64-1.13)$ & $0.33 ; 0$ \\
\hline
\end{tabular}

${ }^{\mathrm{a} R \mathrm{R} s}$ and $95 \%$ Cls were calculated with the DerSimonian and Laird random effect model

'Solid cancers, HIV infection, rheumatologic disease treated with anti-tumor necrosis factor 


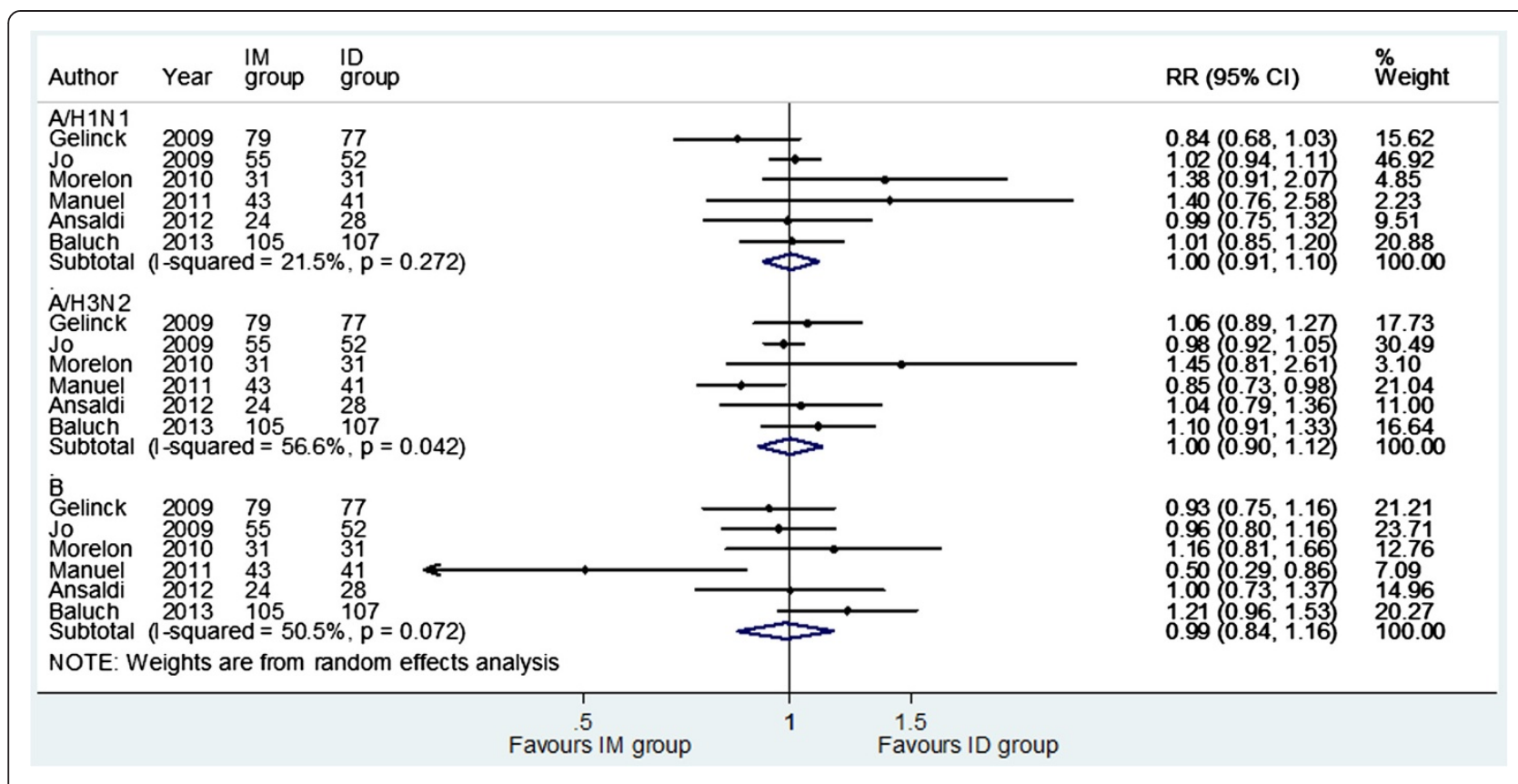

Fig. 2 Forest plots of the risk ratio of seroprotection for intradermal compared with intramuscular administration of influenza vaccine according to strains

transplantation for the same strains, and by injection site and by micro injection system for B strain. Results of meta-analysis on seroconversion did not substantially change in all the stratified analyses (Table 2).

All presented data were derived from random effects models; the results of meta-analyses performed using fixed effects models substantially did not change (data not shown).

\section{Publication bias}

To explore publication bias we searched for similar studies registered in ClinicalTrials.gov and EudraCT databases to

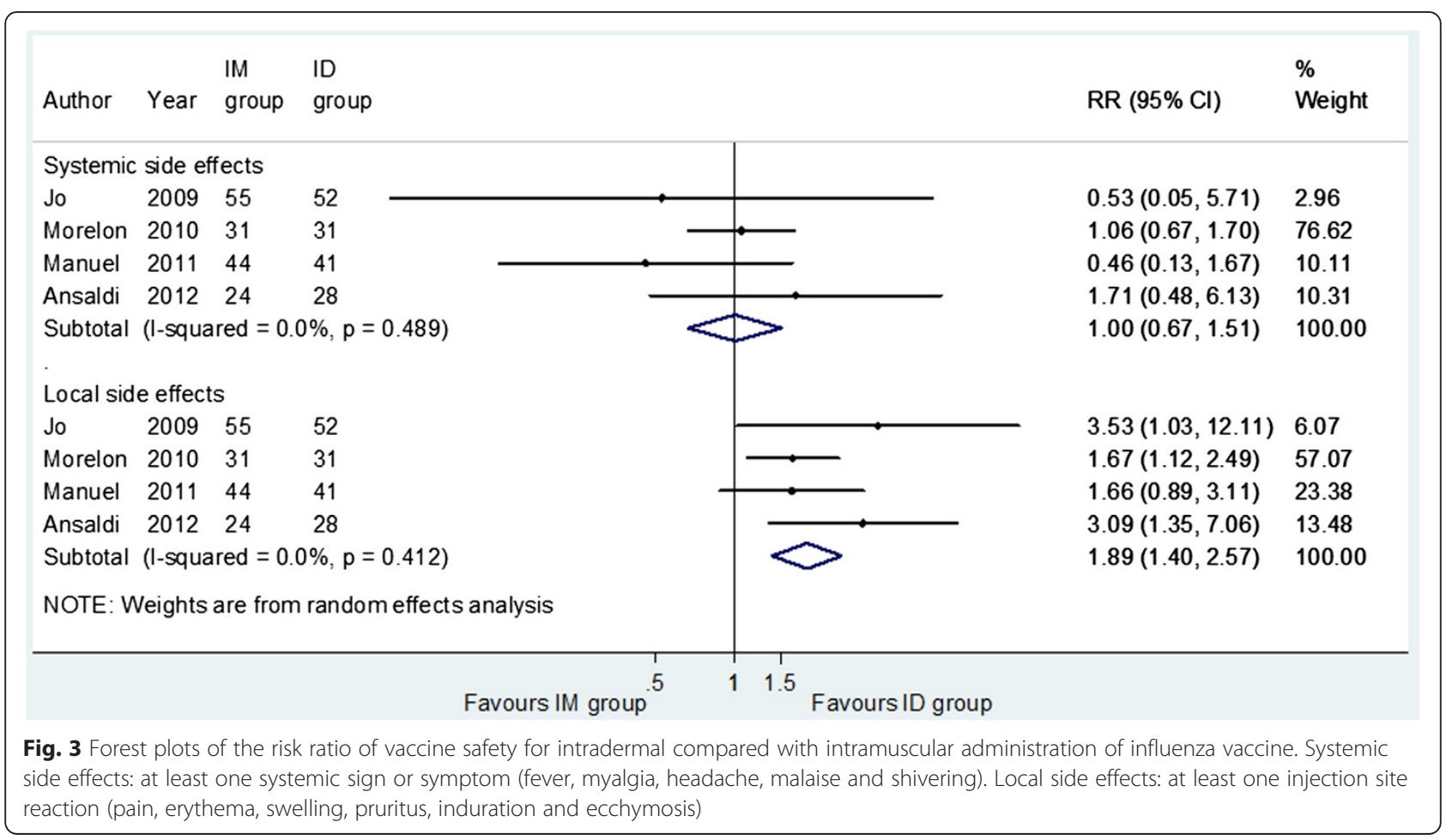


verify the number and eventually the results of similar unpublished studies. We found all of the studies included in our meta-analysis, whereas three studies on the same topic were not published. Of these, one was not completed (the reasons for which were not specified) and 2 were completed in 2010 and in 2012 but were not published.

\section{Discussion}

The present meta-analysis is the first comparing the immunogenicity and safety of a seasonal ID influenza vaccine with the traditional IM formulation in subjects with an impaired immune system.

The major findings provide support to an equivalence of ID formulation immunogenicity in respect to IM influenza vaccine measured through both seroconversion and seroprotection and consistently demonstrated for the three vaccine strains. The equivalence was reached although antigen content was lower in the ID formulation in most included studies, thus providing advantages in terms of dose sparing.

The findings of this meta-analysis are consistent with those of the meta-analysis by Marra et al. [22] that focused more on the immunogenicity of ID influenza vaccination versus IM formulation in subjects who were $\geq 18$ years of age, but excluded immunocompromized subjects. These Authors, in a meta-analysis that included 13 trials, found no difference in the overall immunogenicity outcomes and, interestingly, they found a significant association between increasing doses of the ID formulation with increasing immunogenicity response, and when the ID antigen content was analogous to that of the IM formulation $(15 \mu \mathrm{g})$, the ID vaccine appeared to be superior to the IM formulation for all the strains. This is in line with our results demonstrating an equivalence in studies with lower doses of antigen content in the ID formulation.

The efficacy of influenza vaccination has been extensively evaluated in healthy adults and in the elderly, and recently an umbrella meta-analysis has critically reviewed and re-analysed 15 meta-analyses performed in healthy children, in healthy adults, and in the elderly, and those evaluating the pre-pandemic vaccines (H5N1) and the pandemic 2009 (H1N1) vaccines [23]. Although the results are reported in terms of clinical efficacy and therefore not directly comparable to ours, most seasonal influenza vaccines showed both efficacy and effectiveness at an acceptable or high level for laboratory-confirmed cases and of modest magnitude for clinically-confirmed cases.

A number of reviews [24-26], and two meta-analysis $[27,28]$ have specifically evaluated the role of several vaccinations, including influenza, in immunocompromized patients, since, compared to healthy adults, the immunogenicity of vaccines may be reduced, and the balance between potential benefits and harms of influenza vaccines is hard to establish. In particular, the meta-analyses showed a significant effect in the prevention of influenza-like illness and laboratory confirmed influenza in immunocompromized patients vaccinated with the IM formulation compared to placebo or unvaccinated controls, and no difference in the odds of influenza-like illness compared to vaccinated immunocompetent controls. Less striking results were found for seroconversion and seroprotection rates, and the $\mathrm{Au}$ thors conclude recommending influenza vaccination in immunocompromized patients. Moreover, in all of these reviews, one of the unresolved issues is the role played by new strategies to improve vaccine response, such as ID administration. Therefore, our results meet the need to clarify the usefulness of ID administration in terms of immunogenicity in patients with weakened immune systems.

Our meta-analysis has highlighted that the ID influenza vaccine in these patients was well tolerated without causing excess harm; indeed, the two modes of administration had an overlapping systemic reactogenity and the ID formulation had a higher amount of local adverse reactions than the IM formulation. However, the higher frequency of injection site reactions in the ID formulation is mostly related to erythema, swelling and pruritus, and these adverse events are not generally a cause of concern for patients [29], while the frequency of pain, the most troublesome symptom, is low and comparable to that caused by IM administration $[15,30]$. Thus, based on the results of our meta-analysis, adverse events do not seem to represent a significant safety issue and an obstacle to the acceptability of the ID vaccine. Indeed, previous studies have shown that the acceptability of the ID vaccine is similar $[29,31,32]$ or even greater [33] than that of the IM formulation mainly due to the specific injection device. In particular, Foy et al. [33] found that immediately after receiving the ID influenza vaccine, the overall satisfaction rate was $99.6 \%$ versus $88.2 \%$ after the IM vaccine.

Subjects with weakened immune systems are at "high risk" of adverse outcomes as a result of infection with seasonal influenza, as indicated by the WHO [34]. Therefore, any potential initiatives that may enhance the individual willingness to get vaccinated against influenza should be promoted. In this perspective, the advantages provided by the ID influenza vaccine appear useful and successful [32] and support policies oriented to recommendation of influenza vaccination to immunocompromized patients. In this context efforts are strongly needed to improve general practitioners commitment to adherence to vaccination policies, considering their crucial role in the primary health needs of vulnerable patients $[35,36]$. 


\section{Limitations of the study}

The present meta-analysis also has inherent potential limitations. Few studies have examined the immunogenicity of the two influenza vaccines on immunocompromized patients; therefore achieving sufficient statistical power might be difficult, and a cautious approach in the interpretation of results is warranted, especially for stratified analysis, where comparisons were frequently based on three or four trials.

Moreover, the results might have been affected by publication bias, because only published trials have been included and positive studies are more likely than negative ones to be published. Since the low number of studies included in the meta-analysis did not allow any investigation of publication bias through funnel plots or formal tests [37, 38], we tried to explore registries of RCTs to verify the extent of unpublished studies. We retrieved 9 RCTs on the topic of interest and, of these, three were unpublished. Although delayed publication of RCTs on vaccines has been reported [39], the potential for publication bias exists.

Another possible limitation is the heterogeneity among studies, which included subjects with various degrees of immuno-suppression due to different diseases, and to other factors that might have adversely influenced immune responses (eg. age, co-morbidity). Indeed, the heterogeneity was no more significant when analyses were stratified by type of disease. Moreover, studies used different antigen content in the ID vaccine arm, thus reducing the ability of the meta-analysis to identify a recommended dose.

Further research is required to confirm the results of this meta-analysis, to determine the cost-effectiveness of the ID influenza vaccine and to evaluate whether ID administration in the real world, during seasonal vaccination campaign, will be able to increase the adherence to vaccination due to its greater acceptability.

\section{Conclusions}

The ID influenza vaccine has shown a similar immunogenicity and safety to the IM administration in immunocompromized patients, and it may be a valid option to increase compliance to influenza vaccination in these populations.

\section{Additional file}

Additional file 1: PRISMA checklist. (DOC $69 \mathrm{~kb}$ )

\section{Abbreviations}

ACIP: Advisory Committee on Immunization Practices; Cl: Confidence interval; EMA: European Medicines Agency; FDA: Food and Drug Administration; HA: Hemagglutinin; HIV: Human Immunodeficiency Virus; ID: Intradermal; IM: Intramuscular; RCT: Randomized Controlled Trials; RR: Risk Ratio; WHO: World Health Organization.

\section{Competing interests}

All authors have completed the Unified Competing Interest form at www.icmje.org/coi_disclosure.pdf (available on request from the corresponding author) and declare: that for the specific matter of this research, no support from any organisation for the submitted work; no financial relationships with any organisations that might have an interest in the submitted work in the previous 3 years; no other relationships or activities that could appear to have influenced the submitted work.

\section{Authors' contributions}

CP participated in the conception and design of the study, collected the data, contributed to the data analysis and its interpretation, and wrote the first draft of the article. $F \mathrm{~L}, \mathrm{AB}$, and CGAN collected the data, and contributed to the data analysis and interpretation. MP designed the study, was responsible for the data analysis and interpretation, and wrote the article. CP and MP are guarantors for the study. All authors had full access to all of the data (including statistical reports and tables) in the study and can take responsibility for the integrity of the data and the accuracy of the data analysis. All authors read and approved the final manuscript.

\section{Acknowledgements}

All authors declare that they have no funding received, no current external funding sources for this study and other relationships or activities that could appear to have influenced the submitted work.

The Authors would like to thank Dr Ashour Michael for having checked the English in this manuscript.

Received: 12 March 2015 Accepted: 30 September 2015

Published online: 14 October 2015

\section{References}

1. CDC. Prevention and control of influenza with vaccines. Recommendations of the Advisory Committee on Immunization Practices (ACIP), 2010. MMWR 2010;59(No. RR-8). http://www.cdc.gov/mmwr/pdf/rr/rr5908.pdf. Accessed 15 Jan 2013

2. CDC. Prevention and control of influenza with vaccines. Recommendations of the Advisory Committee on Immunization Practices (ACIP), 2011. MMWR. 2011;60(No. 33):1128-1132. http://www.cdc.gov/mmwr/pdf/wk/mm6033.pdf. Accessed 15 Jan 2013.

3. World Health Organization:Global pandemic influenza action plan to increase vaccine supply: progress report 2006-2008. Geneva, 2009. http:// whqlibdoc.who.int/hq/2009/WHO_IVB_09.05_eng.pdf. Accessed 20 June 2013.

4. World Health Organization: Safety of injections: global facts and figures. Geneva, 2004. http://www.who.int/injection_safety/about/resources/en/ FactAndFiguresInjectionSafety.pdf. Accessed 20 June 2013.

5. Gangappa S, Kokko KE, Carlson LM, Gourley T, Newell KA, Pearson TC. Immune responsiveness and protective immunity after transplantation. Transpl Int. 2008;21:293-303.

6. Zanetti AR, Amendola A, Besana S, Boschini A, Tanzi E. Safety and immunogenicity of influenza vaccination in individuals infected with HIV Vaccine. 2002;20:29-32.

7. Brydak LB, Hryniewicz HJ, Machala M, Horban A. Humoral response to influenza vaccination in HIV-infected patients. Clin Drug Investig. 1999;6:441-9.

8. Chalmers TC, Smith Jr H, Blackburn B, Silverman B, Schroeder B, Reitman D, et al. A method for assessing the quality of a randomized control trial. Controlled Clin Trials. 1981;2:31-49.

9. Jadad AR, Moore RA, Carrol D, Jenkinson C, Reynolds DJ, Gavaghan DJ, et al. Assessing the quality of reports of randomized clinical trials: is blinding necessary? Controlled Clin Trials. 1996;17:1-12.

10. DerSimonian R, Laird N. Meta-analysis in clinical trials. Controlled Clin Trials. $1986 ; 7: 177-88$

11. Mantel N, Haenszel W. Statistical aspects of the analysis of data from retrospective studies of disease. J Natl Cancer Inst. 1959;22:719-48.

12. Higgins JP, Thompson SC. Quantifying heterogeneity in a meta-analysis. Stat Med. 2002;21:1539-58.

13. Moher D, Liberati A, Tetzlaff J, Altman DG. The PRISMA Group (2009): Preferred Reporting Items for Systematic Reviews and Meta-Analyses: The PRISMA Statement. BMJ. 2009;339:b2535 
14. Gelinck LB, van den Bemt $B J$, Marijt WA, van den Bijd AE, Visser LG, Cats $H A$, et al. Intradermal influenza vaccination in immunocompromized patients is immunogenic and feasible. Vaccine. 2009;27:2469-74.

15. Jo YM, Song JY, Hwang IS, Lee J, Oh SC, Kim JS, et al. Dose sparing strategy with intradermal influenza vaccination in patients with solid cancer. J Med Virol. 2009;81:722-7.

16. Morelon E, Noble CP, Daoud S, Cahen R, Goujon-Henry C. Immunogenicity and safety of intradermal influenza vaccination in renal transplant patients who were non-responders to conventional influenza vaccination. Vaccine. 2010;28:6885-90.

17. Manuel O, Humar A, Berutto C, Ely L, Giulieri S, Lien D, et al. Low-dose intradermal versus intramuscular trivalent inactivated seasonal influenza vaccine in lung transplant recipients. J Heart Lung Transplant. 2011;30:679-84.

18. Ansaldi F, Valle $L$, de Florentiis $D$, Parodi $V$, Murdaca G, Bruzzone B, et al. Phase 4 randomized trial of intradermal low-antigen-content inactivated influenza vaccine versus standard-dose intramuscular vaccine in HIV-1infected adults. Hum Vaccin Immunother. 2012;8:1048-52.

19. Baluch A, Humar A, Eurich D, Egli A, Liacini A, Hoschler K, et al. Randomized controlled trial of high-dose intradermal versus standard-dose intramuscular influenza vaccine in organ transplant recipients. Am J Transplant. 2013;13:1026-33.

20. Khanlou H, Sanchez S, Babaie M, Chien C, Hamwi G, Ricaurte JC, et al. The safety and efficacy of dose-sparing intradermal administration of influenza vaccine in human immunodeficiency virus-positive patients. Arch Intern Med. 2006;166:1417.

21. Manuel O, Humar A, Chen MH, Chernenko S, Singer LG, Cobos I, et al. Immunogenicity and safety of an intradermal boosting strategy for vaccination against influenza in lung transplant recipients. Am J Transplant. 2007;7:2567-72

22. Marra F, Young F, Richardson K, Marra CA. A meta-analysis of intradermal versus intramuscular influenza vaccines: immunogenicity and adverse events. Influenza Other Resp Viruses. 2013;7:584-603.

23. Manzoli L, loannidis JPA, Flacco ME, De Vito C, Villari P. Effectiveness and harms of seasonal and pandemic influenza vaccines in children, adults and elderly. A critical review and re-analysis of 15 meta-analyses. Hum Vaccin Immunother. 2012:8:851-62.

24. Kumar D, Blumberg EA, Danziger-Isakov L, Kotton CN, Halasa NB, Ison MG, et al. Influenza vaccination in the organ transplant recipient: review and summary recommendations. Am J Transplant. 2011;11:2020-30.

25. Englund J, Feuchtinger T, Ljungman P. Viral infections in immunocompromised patients. Biol Blood Marrow Transplant. 2011;17:S2-5.

26. Kunisaki KM, Janoff EN. Influenza in immunosuppressed populations: a review of infection frequency, morbidity, mortality, and vaccine responses. Lancet Infect Dis. 2009;9:493-504.

27. Beck CR, McKenzie BC, Hashim AB, Harris RC, Nguyen-Van-Tam JS. Influenza vaccination for immunocompromised patients: systematic review and meta-analysis by etiology. J Infect Dis. 2012;206:1250-9.

28. Beck CR, McKenzie BC, Hashim AB, Harris RC, Zanuzdana A, Agboado G, et al. Influenza vaccination for immunocompromised patients: systematic review and meta-analysis from a public health policy perspective. PLoS One. 2011;6:e29249.

29. Reygrobellet C, Viala-Danten M, Meunier J, Weber F, Nguyen VH. Perception and acceptance of intradermal influenza vaccination: Patient reported outcomes from phase 3 clinical trials. Hum Vaccin. 2010;6:336-45.

30. Arnou R, Icardi G, De Decker M, Ambrozaitis A, Kazek MP, Weber F, et al. Intradermal influenza vaccine for older adults: A randomized controlled multicenter phase III study. Vaccine. 2009;27:7304-12

31. Durando P, Alicino C, Alberti M, Sticchi L, Turello V, Marensi L, et al. Acceptance and safety of the intradermal influenza vaccine among the elderly in Italy: an on-field national study. Adv Ther. 2012;29:312-26.

32. Arnou $R$, Frank $M$, Hagel $T$, Prébet $A$. Willingness to vaccinate or get vaccinated with an intradermal seasonal influenza vaccine: a survey of general practitioners and the general public in France and Germany. Adv Ther. 2011;28:555-65.

33. Foy JE, Hendriksz $T$, Malouf $P$, Tobin A. Acceptability of fluzone intradermal vaccine to patients and vaccine administrators. J Am Osteopath Assoc 2013;113:134-43.

34. World Health Organization: Resolution of the World Health Assembly (WHA 56.19). Prevention and control of influenza pandemics and annual epidemics. Presented at: WHA 10th Plenary Meeting. 28 May 2003.
http://apps.who.int/gb/archive/pdf_files/WHA56/ea56r19.pdf. Accessed 20 June 2013.

35. Pavia M, Foresta MR, Carbone V, Angelillo IF. Influenza and pneumococcal immunization in the elderly: knowledge, attitudes, and practices among general practitioners in Italy. Public Health. 2003;117:202-7.

36. Manuti B, Rizza P, Pileggi C, Bianco A, Pavia M. Assessment of perceived health status among primary care patients in Southern Italy: findings from a cross-sectional survey. Health Qual Life Outcomes. 2013;11:93.

37. Lau J, loannidis JP, Terrin N, Schmid CH, Olkin I. The case of the misleading funnel plot. BMJ. 2006;333:597-600.

38. Ioannidis JP, Trikalinos TA. The appropriateness of asymmetry tests for publication bias in meta-analyses: a large survey. CMAJ. 2007;176:1091-6.

39. Manzoli L, Flacco ME, D'Addario M, Capasso L, De Vito C, Marzuillo C, et al. Non-publication and delayed publication of randomized trials on vaccines: survey. BMJ. 2014;348:93058.

\section{Submit your next manuscript to BioMed Central and take full advantage of:}

- Convenient online submission

- Thorough peer review

- No space constraints or color figure charges

- Immediate publication on acceptance

- Inclusion in PubMed, CAS, Scopus and Google Scholar

- Research which is freely available for redistribution 